\title{
APPLICATIONS OF IMAGING SPECTROSCOPY FOR NON-METALLIC MINERAL EXPLORATION
}

\author{
Hrishikesh Kumar ${ }^{1 *}$, A.K. Sharma ${ }^{1}$ and A.S Rajawat ${ }^{1}$ \\ ${ }^{1}$ Space Applications Centre, Ahmedabad, Gujarat, India- (hrishikesh, sharma_arun, asrajawat)@ sac.isro.gov.in
}

Commission V, SS: Natural Resource Management

KEY WORDS: Imaging spectroscopy, AVIRIS-NG, mineral mapping

\begin{abstract}
:
Imaging spectroscopy/hyperspectral remote sensing technique acquires images in a very narrow and contiguous spectral bands. High spectral resolution data provided by imaging spectrometers enables remote compositional mapping of earth surface. In the present study, we demonstrate the potentials of airborne AVIRIS-NG datasets for identification and mapping of non-metallic minerals. Several minerals such as carbonates, sulphates and phyllosilicate exhibit diagnostic absorption feature in Short Wave Infrared Region (SWIR) (2.0-2.5 $\mu \mathrm{m})$. Therefore, mapping of wavelength of deepest absorption in SWIR is very useful for exploratory earth surface composition/mineral mapping. To map the mineralogical diversity in the parts of Banswara region, Rajasthan, wavelength of deepest absorption feature and absorption band depth in SWIR region was calculated at each pixel. It was found that majority of pixels showed absorption near $\sim 2.31,2.33$ and $2.20 \mu \mathrm{m}$. Detailed analysis of spectra of image revealed dolomite as dominant mineral at pixels showing deepest absorption at $2.31 \mu \mathrm{m}$. Calcite and clays were found to be present at pixels showing deepest absorption feature near 2.33 and $2.20 \mu \mathrm{m}$ respectively. It is noted that mapping wavelength position of deepest feature is a very fast and reliable indicator of mineralogy. The mineral map of calcite and dolomite shall be useful for locating new mining prospect in the region.
\end{abstract}

\section{INTRODUCTION}

Hyperspectral remote sensing or imaging spectrometry is a technique in which images are acquired in very narrow, contiguous spectral band (Goetz et al., 1985). It has emerged as powerful, rapid, inexpensive and non-destructive technique and is commonly used in identification of minerals and in some instances determination of their abundance (Hunt and Ashley, 1979, Goetz et al., 1985; Lang et al. 1987; Kruse, 1988; Pieters and Mustard, 1988).

For geological applications mapping of mineralogy is extremely important for plethora of applications such as mineral exploration, active fault and geo-environmental studies. Carbonates, sulphates and phyllosilicate exhibit diagnostic absorption feature in Short Wave Infrared Region (SWIR) (2.0$2.5 \mu \mathrm{m}$ ) which aids in their identification and mapping. Several workers have demonstrated the application of hyperspectral datasets for mineralogical mapping (e.g. Kruse et al., 1993, Clark et al., 2003). In these methods, mineral mapping is done by comparing reference spectra with image spectra. The algorithms use shape of absorption features to identify the minerals. Therefore, subtle mineralogical/chemical variations within a mineral group arising from minor shift in wavelength position is not captured by them. For example, wavelength of deepest absorption of white mica near $2.0 \mu \mathrm{m}$ varies with substitution of aluminium (Clark et al., 1999) while the overall shape of the absorption feature is nearly same. Similarly, subtle variations in wavelength of deepest absorption assist in discrimination between calcite and dolomite (Gaffey, 1986). Recent advances in hyperspectral imaging technology has led to development of sensors with very high spectral resolutions capable of resolving subtle differences in wavelength position of absorption feature.

Here, we use high spatial and spectral resolution images of AVIRIS-NG for mapping carbonates and clays based on wavelength position of their deepest absorption features in parts of Banswara, Rajasthan. Further, the utility of this technique in identification of subtle changes in chemistry of minerals is discussed.

\section{STUDY AREA}

Banswara is located at southernmost part of Rajasthan, India (Figure-1). The area consists of pre-Aravalli basement rocks of Bhilwara Supergroup, Aravalli metasediments, post Aravalli intrusive and younger flows of Cretaceous period. The Aravalli metasediments comprised of quartzite, mica schists, quartz-

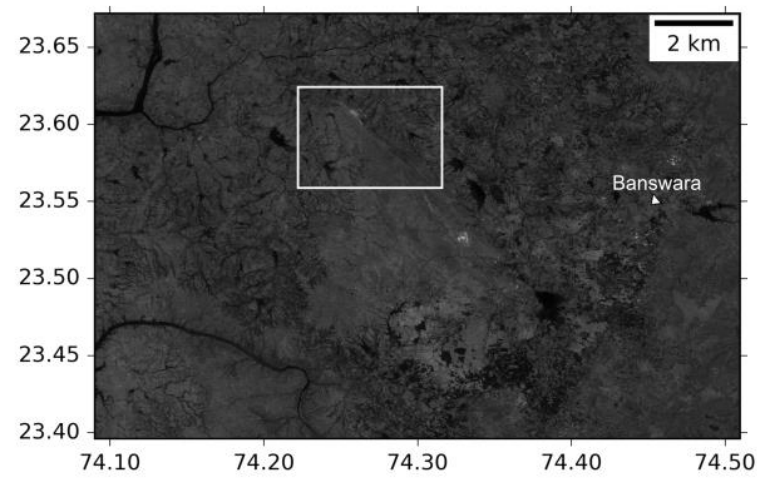

Figure 1. Location map of the study area overlaid on optical imagery of LISS-IV. The white coloured inset shows extent of AVIRIS-NG dataset

chlorite schist, phyllites, marbles, gneisses and conglomerates. Post-Aravalli intrusive include granites, pegmatite, amphibolites and quartz veins. Banswara region is famous for its extensive cement grade Aravalli limestone deposits.

\section{DATA USED}

In the present study, we have used airborne datasets of AVIRISNG collected over India. AVIRIS-NG is an airborne imaging spectrometer developed by Jet Propulsion Laboratory (Green et al., 1998). The sensor acquires data in four hundred twenty-five 
contiguous spectral band in wavelength range 0.4-2.5 $\mu \mathrm{m}$. The dataset was acquired at very high spectral $(5 \mathrm{~nm})$ and spatial $(4$ m) resolution.

\section{METHODOLOGY}

\subsection{Mapping deepest absorption feature}

Wavelength of deepest absorption of any minerals is wavelength corresponding to its deepest absorption feature in continuum removed reflectance spectra. Minerals such as clay show diagnostic absorption feature at $2.20 \mu \mathrm{m}$ while carbonates show absorption feature near $2.33 \mu \mathrm{m}$. Iron oxides have absorption feature near $1.0 \mu \mathrm{m}$. Several mineral groups such as carbonates, epidotes and phyllosilicates have diagnostic absorption feature in Short Wave Infrared Region (SWIR) of electromagnetic spectrum. Therefore, mapping of wavelength corresponding to deepest absorption feature in SWIR may be useful indicator for mineral group present.

Absorption features in reflectance spectra of minerals are superimposed over the continuum which is a convex hull fit to the top of the reflectance spectra. The continuum of the spectra was removed using technique given by Clark and Roush, 1984.The process of continuum removal normalizes the spectra and is prerequisite the determination of absorption wavelength and depth of absorption feature. To calculate the wavelength position of deepest absorption feature, methodology described in Rodgers et al., (2012) was adopted. In this method, wavelength position corresponding to deepest absorption feature is determined from continuum removed spectra. Considering wavelength corresponding to lowest reflectance as centre, two adjacent wavelengths located on either side of centre are chosen and a quadratic polynomial is fitted through these three points. This can be represented by the following equation:

$w(x)=a x^{2}+b x+c$

Where $\mathrm{x}$ represents wavelength and $\mathrm{w}(\mathrm{x})$ is interpolated reflectance and $a, b, c$ are coefficients of the equation. The minimum value of this equation is represented by:

$w_{\min }=\frac{-b}{2 a}$

Where $w_{\min }$ is interpolated wavelength position corresponding to minimum reflectance. Minimum interpolated wavelength is calculated at each pixel using this approach.

\subsection{Depth of absorption feature}

Depth of deepest absorption feature is calculated from continuum removed spectra as follows:

$\mathrm{D}_{\mathrm{CR}}=1-\mathrm{R}_{\mathrm{CR}}$

Where $D_{C R}$ is depth of absorption feature of continuum removed spectra and $R_{C R}$ is continuum removed reflectance.

\subsection{Masking of vegetation and water}

In order to map minerals/altered minerals in study region we first mask the vegetation cover as it may adversely affect the mineral mapping. In order to mask the vegetation, Normalized Difference Vegetation Index (NDVI) was used. Water is masked by Normalized Difference Water Index (NDWI). By masking vegetation and water bearing pixels, it was made sure that mineral mapping is done at rock exposures and soil pixels only.

\section{RESULTS AND DISCUSSIONS}

\subsection{Depth of deepest absorption feature}

Shown in Figure-2 is depth of deepest absorption feature in SWIR region. Magnitude of depth of absorption feature varies from 0.01 to 0.35. Depth of absorption feature depends on intrinsic absorption strength, grain size and abundance of the material at the pixel. If we consider the variations in grain size as constant across the study area, then depth of absorption feature may be related to material abundance. However, presence of noise in reflectance spectra, intimate mixing and degree of weathering complicates the relationship between depth and abundance of the material. It was noticed that spectra of minerals contain several kinks that are unrelated to mineral absorption feature. These kinks arise mostly due to residual atmospheric artefacts and internal noise of the sensor. Therefore, low band depth value $(<0.03)$ pixels are considered to be contributed by noise. The pixels showing band depth value less than 0.03 have been masked in subsequent analysis.

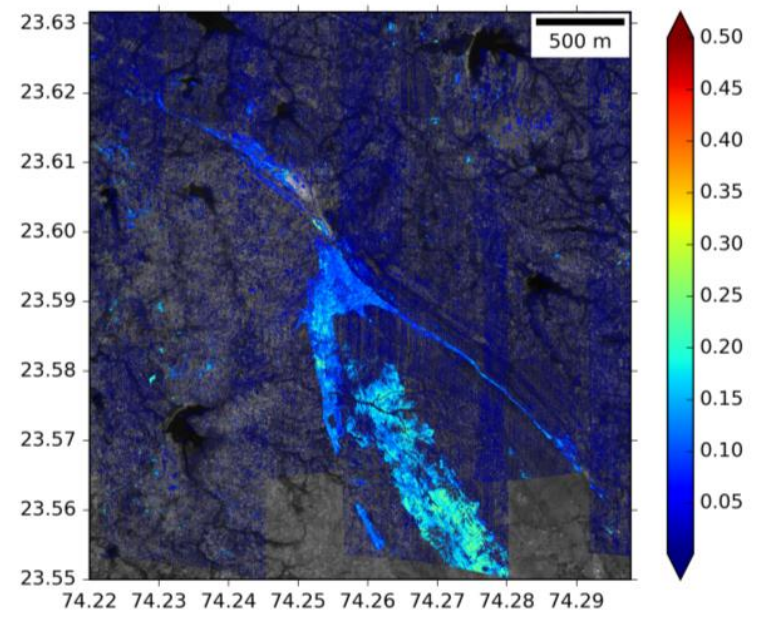

Figure 2. Band depth of the deepest absorption feature in SWIR region. Areas with low band depth values $(<0.03)$ indicate residual atmospheric and sensor artefacts and are masked

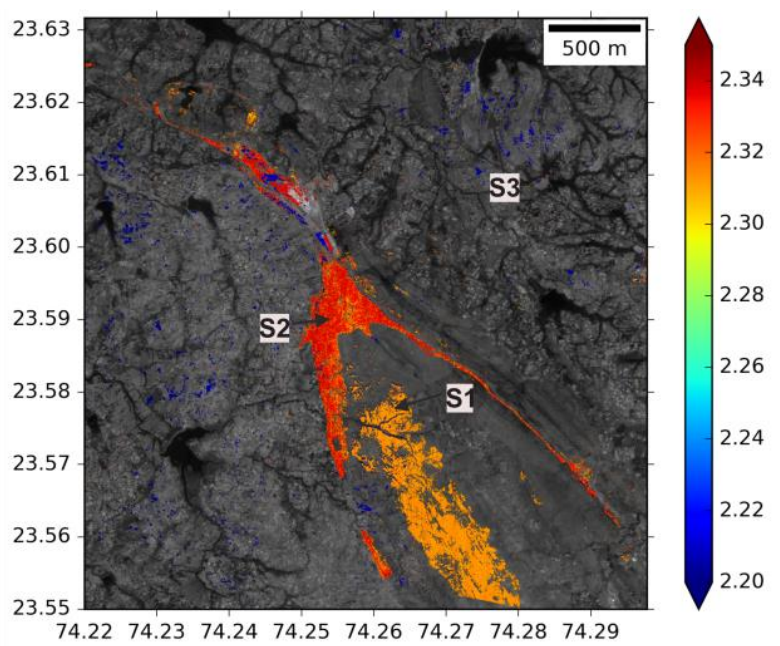

Figure 3. Wavelength of deepest absorption feature in SWIR regions. Regions in reddish brown, orange and bluish colour 
indicate deepest absorption wavelength near $2.33 \mu \mathrm{m}, 2.31 \mu \mathrm{m}$ and $2.20 \mu \mathrm{m}$. The locations marked as S1, S2 and S3 represent locations identified for detailed spectral analysis

Figure 3 shows map of wavelength of deepest absorptions occurring in Short Wave Infra-Red (SWIR) region. Vegetated pixels and pixels with low band depth value are masked using methodology described above. It is observed that the dominant wavelength of absorption in northern part of the image is $2.33 \mu \mathrm{m}$. In southern portions of the image, deepest absorption occurs at $2.31 \mu \mathrm{m}$. Several small patches showing absorption feature near $2.20 \mu \mathrm{m}$ are also observed.

Absorption features in 2.30-2.35 $\mu \mathrm{m}$ occurs mainly due $\mathrm{Mg}-\mathrm{OH}$ bonding while absorptions near $2.20 \mu \mathrm{m}$ is due to AL-OH bonding. In order to identify the minerals, we analysed the reflectance spectra of minerals from these spatial locations.

\subsection{Spectral analysis}

Detailed analysis of image spectra of regions was performed to identify the minerals present in the area. Representative image spectra were extracted from locations showing deepest absorption wavelength near 2.31, 2.33 and $2.20 \mu \mathrm{m}$ and are shown in Figure-3. Intercomparison of representative image spectra and library spectra was performed by spectral Angle Mapper (SAM) technique to identify the minerals. Here we have used United States Geological Services (USGS) mineral library spectra. Chemical composition and mineral type of library/reference spectra are known apriori. SAM technique computes angle between the reference spectra (library or field spectra) and image spectra. The library spectra for which the image spectra show the lowest angle is considered as best match. Unknown spectra is considered of mineral for which it showed best match with library spectra.
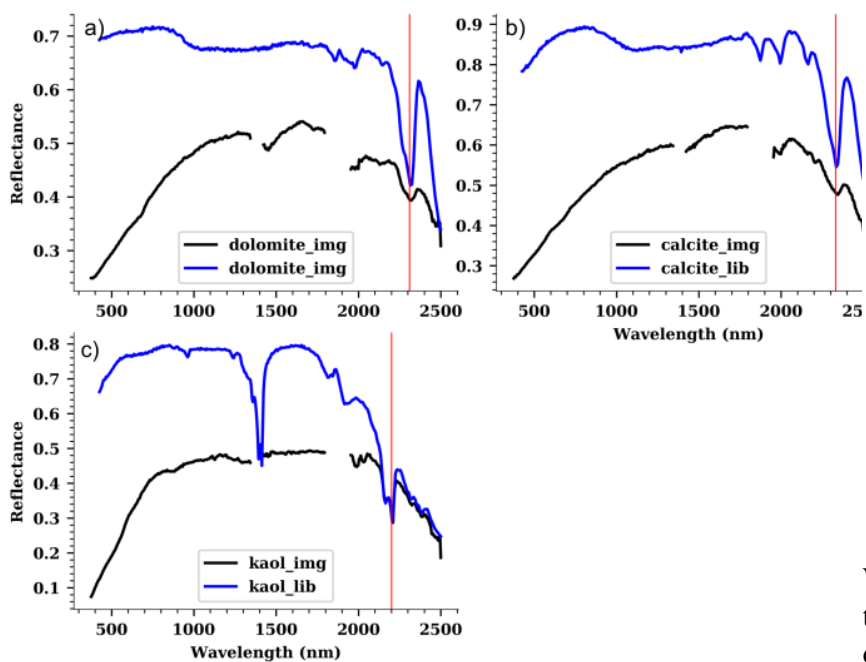

Figure 4. Inter-comparison of reflectance spectra of library and image for dolomite (a), calcite (b) and kaolinite (c). Red lines are placed at 2.31, 2.33 and $2.20 \mu \mathrm{m}$ in figure $\mathrm{a}, \mathrm{b}$ and $\mathrm{c}$. The image spectra were collected from locations marked as S1, S2 and $\mathrm{S} 3$ in figure-3

Figure-4a shows inter-comparison of library and image spectra of dolomite showing deepest absorption wavelength (marked as $\mathrm{S} 1$ in Figure-3) at $\sim 2.315 \mu \mathrm{m}$. It is noticed that the wavelength deepest of absorption feature $(2.315 \mu \mathrm{m})$ and its shape matches well with the image spectra indicating presence of dolomite. Similarly, the spectral matching (Figure-4b) of image spectra acquired from locations showing deepest absorption at $2.33 \mu \mathrm{m}$ (marked as S2 in Figure-3) indicates presence of calcite. Figure $4 \mathrm{c}$ shows inter-comparison of image and library spectra of region showing deepest absorption feature near $2.20 \mu \mathrm{m}$. Based on diagnostic absorption feature and wavelength of deepest absorption feature, the mineral is identified as kaolinite.

The absorption features of carbonates as seen in wavelength range $2.31-2.35 \mu \mathrm{m}$ is due to vibrational processes. The planar carbonate ion has four modes of vibrations (Clark, 1999). All the four vibrational absorption feature occur in wavelength range of 9-15 $\mu \mathrm{m}$. However, the overtones of fundamental vibrational absorption feature of carbonate ions occur near SWIR region in wavelength range 2.31-2.35 $\mu \mathrm{m}$. The shape and wavelength of absorption in this region is considered as diagnostic for mapping of carbonate minerals by reflectance spectroscopy.

Analysis of library spectra of kaolinite (Figure-4c) reveals absorption features at 1.4, 1.9 and $2.2 \mu \mathrm{m}$. The absorption occurring at $1.4 \mu \mathrm{m}$ is due to presence of hydroxyl ions while $1.9 \mu \mathrm{m}$ absorption features arises due to water in crystal structure. Doublet at $2.20 \mu \mathrm{m}$ occurs due to metal-OH (Al-OH) bonding. In terrestrial remote sensing, absorptions at 1.4 and $1.9 \mu \mathrm{m}$ are adversely affected by atmospheric water vapour absorptions and are not of much use for mineral identification and mapping. However, the doublet near $2.20 \mu \mathrm{m}$ is unique feature of mineral kaolinite and aid in its identification.

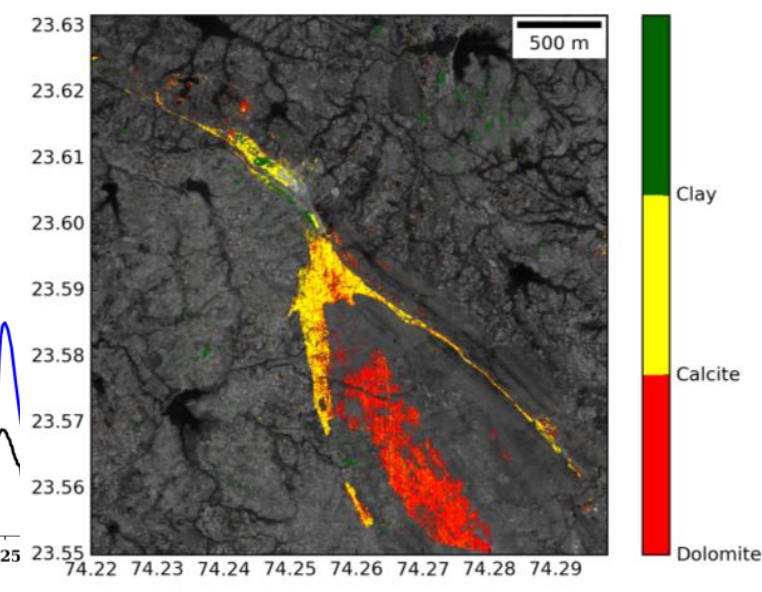

Figure 5. Map showing spatial distribution of calcite (yellow color), dolomite (red) and clay (blue) minerals. Presence of calcite indicates relatively pure marble while dolomite indicates occurrence of dolomitic marble

We have applied a decision rule which uses wavelength range to extract the spatial extent of calcite, dolomite and clays. In the decision rule, we have assigned the pixels whose deepest absorption range lies within $2.30-2.32 \mu \mathrm{m}$ as dolomite while those having absorption in wavelength range $2.334 .2 .34 \mu \mathrm{m}$ as calcite. The pixels whose absorption feature occurs near 2.20 $\mu \mathrm{m}$ are classified as clay. Therefore, the resulting map contains spatial extent of calcite, dolomite and clays (Figure-5). These maps can also be interpreted in terms of quality of marble deposits. Relatively pure marble (calcite rich) are exposed on northern part (Figure-5) while dolomitic marbles are present in southern part. Several marble mines are also observed in pure marble regions. The spatial extent of pure marble deposits as mapped in this study may be considered as prospective region for future marble exploration programmes. Further, mapping of 
dolomite in the region has important implication for phosphate exploration as phosphates have been found to be associated with dolomites. Dolomites are also host rock for base metal mineralization in Aravalli metasediments.

\section{CONCLUSION}

The present study demonstrates the application of AVIRIS-NG datasets in mapping clays and carbonates in parts of Banswara region. It has been found that mapping wavelength of deepest absorption feature in SWIR region is an effective technique of assessing the surficial mineralogical diversity. The map of wavelength of deepest absorption feature helps in identification of areas of interest for detailed spectral investigation and mineral identification. Further, map showing subtle variations wavelength absorption features near 2.20 and $2.32 \mu \mathrm{m}$ may interpreted in terms of subtle mineralogical variations. Detailed spectral analysis of areas of interest and matching image spectra with library spectra helps in identification of minerals present. Based on spectral analysis of spectra, it was found that calcite is spectrally dominant mineral present in northern part of the study area while the southern part is dominated by dolomite. Localized patches of clay minerals are also mapped in the region. High spectral resolution $(5 \mathrm{~nm})$ of AVIRIS-NG imaging spectrometer enabled discrimination among the carbonate species (calcite and dolomite) based subtle difference in wavelength of their absorption feature. By applying rule based thresholding on wavelength of deepest absorption feature image, we mapped the spatial extent of calcite, dolomite and clay minerals in the region. The mapped extent of calcite and dolomite may be helpful in prioritising marble exploration activities in the region. Mapping of dolomite in the region has important implication for phosphate exploration as phosphates have been found to be associated with dolomites. Further, dolomitic rocks are also host rock for base metal mineralization in Aravalli metasediments. Therefore, mapping their spatial extent has implications for mineral exploration in study area.

\section{ACKNOWLEDEMENTS}

Authors are thankful to Shri D.K. Das, Director, Space Applications Centre and Dr. Rajkumar, DD-EPSA for their valuable support and encouragement during course of study.

\section{REFERNCES}

Clark, R. N., \& Roush, T. L. 1984. Reflectance spectroscopy: Quantitative analysis techniques for remote sensing applications. Journal of Geophysical Research: Solid Earth, 89(B7), 6329-6340.

Clark, R.N., 1999. Spectroscopy of rocks and minerals, and principles of spectroscopy. Manual of remote sensing, 3 (3-58), pp.2-2.

Gaffey, S.J., 1986. Spectral reflectance of carbonate minerals in the visible and near infrared (O. 35-2.55 microns); calcite, aragonite, and dolomite. American Mineralogist, 71(1-2), pp.151-162.

Goetz, A. F. H., Vane, G., Solomon, J. E., and Rock, B. N. 1985. Imaging spectrometry for earth remote sensing: Science, 228, 1147-1153.
Green, R.O., Eastwood, M.L., Sarture, C.M., Chrien, T.G., Aronsson, M., Chippendale, B.J., Faust, J.A., Pavri, B.E., Chovit, C.J., Solis, M., Olah, M.R., and Williams, O. (1998). Imaging Spectroscopy and the Airborne Visible/Infrared Imaging Spectrometer (AVIRIS). Remote Sensing of Environment, 65(3), 227-248.

Hunt, G. R., \& Ashley, R. P. 1979. Spectra of altered rocks in the visible and near infrared. Economic Geology, 74(7), 16131629.

Kruse, F. A. 1988. Use of airborne imaging spectrometer data to map minerals associated with hydrothermally altered rocks in the northern Grapevine Mountains, Nevada, and California. Remote Sensing of Environment, 24(1), 31-51.

Lang, H. R., Adams, S. L., Conel, J. E., McGuffie, B. A., Paylor, E. D., and Walker, R. E. 1987. Multispectral remote sensing as stratigraphic tool, Wind River Basin and Big Horn Basin areas, Wyoming. American Association of Petroleum Geologists Bulletin, 71(4), 389-402.

Pieters, C. M., \& Mustard, J. F. 1988. Exploration of crustal/mantle material for the earth and moon using reflectance spectroscopy. Remote Sensing of Environment, 24(1), 151-178.

Rodger, A., Laukamp, C., Haest, M., \& Cudahy, T. 2012. A simple quadratic method of absorption feature wavelength estimation in continuum removed spectra. Remote Sensing of Environment, 118, 273-283. 